\title{
REPRESENTAÇÃO EM MALHAS 3D A PARTIR DE DADOS DE TEXTURA DO SOLO INTERPOLADOS MEDIANTE REDE NEURAL ARTIFICIAL: ESTUDO DE CASO FESCON - PONTA GROSSA - PR \\ REPRESENTATION IN 3D MESHES FROM THE INTERPOLATED SOIL TEXTURE DATA BY ARTIFICIAL NEURAL NETWORK: CASE STUDY FESCON - PONTA GROSSA - PR
}

\author{
Giuvane Conti ${ }^{1}$, Kelly Lais Wiggers ${ }^{1}$, Selma Regina Aranha Ribeiro ${ }^{1}$ \\ ${ }^{1}$ Universidade Estadual de Ponta Grossa (UEPG), Ponta Grossa, PR, Brasil
}

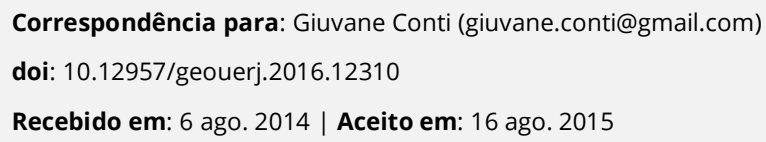

\section{RESUMO}

As propriedades físicas do solo possuem grande impacto em seu comportamento, e estas características resultam na classificação do perfil e aptidão do solo. Em se tratando de Agricultura de Precisão, é importante identificar no solo sua distribuição espacial granulométrica ou textura. Desta forma, a partir de dados granulométricos georreferenciados (areia, silte e argila) coletados de solos de uma gleba da Fazenda Escola Capão-da-Onça (FESCON Ponta Grossa - PR), foi realizada a interpolação, utilizando Função de Base Radial (RBF) e treinamento supervisionado por Rede Neural Artificial (RNA), comparando os resultados obtidos em um modelo 3D, a fim de verificar o desempenho da RNA utilizada. Verificou-se principalmente que as representações da RNA com o atributo areia foi suavizada quando interpolado os dados granulométricos em relação ao RBF. Já os atributos argila e silte ocorreu algumas variações entre RNA e RBF, não suavizando sempre.

Palavras-chave: Dados de textura do solo; redes neurais artificiais; representação em malhas 3D.

\section{ABSTRACT}

The physical properties of the soil have great impact on their behavior, and these characteristics result in classification of the profile and soil suitability. In the case of Precision Agriculture is important to identify in the soil particle size space distribution or texture. Thus, from granulometric georeferenced data (sand, silt and clay) soils collected from a farmland Farm School Capão-da-Onça (FESCON Ponta Grossa - PR), was performed interpolation using Radial Basis Function (RBF) and supervised training for Artificial Neural Network (ANN), comparing the results obtained on a 3D model in order to verify the performance of the RNA used. It was found that especially the representations of RNA with the sand attribute was smoothed when interpolated the granulometric data in realation to RBF. The attributes clain and silt had some variations between $A N N$ and RBF, it doesn't always smoothed.

Keywords: interpolates soil texture; artificial neural network; 3D meshes representation.

\section{INTRODUÇÃO}

As técnicas de Sistemas de Informação Geográfica (SIG) são adequadas para estudos do meio ambiente, visto que proporcionam a manipulação, organização e modelagens dos dados obtidos em informações relevantes. 
O termo Sistemas de Informações Geográficas ( $\mathrm{SIG}$ ) refere-se àqueles sistemas que efetuam o tratamento computacional de dados geográficos. Um SIG armazena a geometria e os atributos dos dados que estão georreferenciados, isto é, localizados na superfície terrestre e numa projeção cartográfica determinada. Os dados tratados em geoprocessamento têm como principal característica a diversidade de fontes geradoras e de formatos apresentados. (ASSAD, 1998).

Um modelo de representação de dados em SIG é o modelo digital de elevação ou de terreno (MDE ou MDT), como por exemplo, a grade regular. Esta grade pode gerar uma representação matricial onde cada elemento da matriz está associado a um número referente a um atributo, tal como altitude, cota, temperatura, textura de solos, dentre outros. Para a geração da grade, torna-se necessário estimar, a partir de interpoladores matemáticos, os valores para as células que não possuem medidas de atributos ou numéricas. Neste estudo utiliza-se o MDE para a representação da textura do solo, isto é modelos de três teores de areia, silte e argila.

As propriedades físicas do solo possuem grande impacto em seu comportamento e em como deve ser efetuado seu manejo. Suas propriedades físicas são caracterizadas pela cor, textura (granulometria), estrutura, porosidade, consistência e permeabilidade. Todas essas características resultam na classificação do perfil e aptidão do solo (BRADY e WEIL, 2008). O termo granulometria é utilizado para identificar o conjunto de partículas do solo, desde as mais finas, como argila até as mais grosseiras, como cascalho e são divididas em 3 grupos: areia, silte e argila (IBGE, 2007).

A necessidade de incrementar a produção agrícola é uma realidade para a humanidade, neste contexto as técnicas e métodos são imprescindíveis na agricultura. Para o desenvolvimento dela, voltado à preservação do meio ambiente, respeitando a heterogeneidade dos solos e usando adequadamente dos insumos agrícolas, a Agricultura de Precisão (AP) é um fato.

Segundo MAPA (2011), a AP é um sistema de gerenciamento agrícola, baseado na variação espacial das propriedades do solo e das plantas encontradas nas lavouras. Seu objetivo é a otimização do lucro, sustentabilidade e proteção do meio ambiente. 
Em se tratando de AP / culturas é importante identificar no solo sua distribuição espacial granulométrica ou textura do solo. A fração areia, por possuir o maior tamanho, permite maior permeabilidade à água e ao ar do solo, possui baixa capacidade de retenção de água e é considerada não-coesivas. A fração silte possui poros menores, porém em maior quantidade, retendo mais água e menor drenagem do que areia. A fração argila, por possuir um diâmetro reduzido, apresenta grande área superficial específica, o que leva a uma alta retenção de água e fluxo lento de ar e também alta pegajosidade quando úmida e alta coesão quando seca (Brady e Weil, 2008), devido aos fatos, a fração do solo que mais influencia em seu comportamento físico é a argila (Reichardt e Timm, 2004). A fração argila também é primordial no que diz respeito a fertilidade do solo, capacidade de troca de cátions, disponibilidade de nutrientes, capacidade de armazenamento de água, tendência à compactação, porosidade e permeabilidade, mais detalhes sobre fração argila em PAIVA NETO, 1942.

Como já mencionado, a interpolação espacial é o procedimento para se estimar valores de propriedades de locais não amostrados, baseando-se em valores de dados observados em locais conhecidos (Burrough, 1986).

Para interpolar dados espacialmente é necessário a construção de uma malha envolvendo todo o domínio dos pontos amostrais. Segundo Carmo (2001) apud Mazzini e Schettini (2009), há diversos métodos de gradeamento, sendo capazes de gerar grades regulares e irregulares.

Segundo Mazzini e Schettini (2009), a Função de Base Radial (RBF) é um conjunto de métodos de interpolação exatos. A maioria dos métodos são derivações de spline, com características similares uns dos outros. 0 referido autor também destaca que o método de derivação multi-quadrático é o padrão automático no Surfer@, pois é considerado o melhor na maioria dos casos.

O objetivo deste trabalho é, a partir de dados georreferenciados coletados de solos de uma gleba da Fazenda Escola Capão-da-Onça (FESCON Ponta Grossa - PR), realizar a interpolação, utilizando o RBF (Função de Base Radial) e treinamento supervisionado por Rede Neural Artificial (RNA), 
comparando os resultados obtidos em um modelo 3D, a fim de verificar o desempenho da RNA utilizada.

\section{Redes Neurais Artificiais}

As RNA (Redes Neurais Artificiais) são motivadas pelo princípio do cérebro humano processar informações de forma diferente do computador convencional. Ou seja, o cérebro humano é considerado um computador altamente complexo, não linear e paralelo, com capacidade de organizar seus constituintes estruturais conhecidos por neurônios e também realiza certos processamentos como reconhecimento de padrões, percepção e controle motor de forma mais eficiente que um computador digital (HAYKIN, 1999).

O autor referido acima define a rede neural como uma máquina projetada para modelar a maneira como o cérebro realiza tarefas e funções de interesse e é implementada por componentes eletrônicos ou simulada por programação em um computador.

Rezende (2005) destaca que as RNA são capazes de resolver problemas de aproximação, predição, categorização, otimização e classificação. Alguns exemplos de utilização são: reconhecimento de caracteres, reconhecimento de voz, predições de séries temporais e modelagem de processos.

Segundo Chen e Leou (2012) o uso de redes neurais com interpoladores possui resultados rápidos com alta complexidade computacional para seleção de conjunto de cores em imagens. Gorgens et al (2009) afirma que a interpolação linear como método de normalização fornece melhores resultados e a equalização dos dados melhora a capacidade de predição da rede neural. Para Nourani e Babakhani (2012) a integração de redes neurais com o interpolador RBF apresenta resultados satisfatórios no cálculo de infiltração de barragens de terra.

Define-se aprendizagem no contexto de RNA como o processo pelo qual os parâmetros livres de uma RNA são adaptados através de um processo de estimulação pelo ambiente no qual a rede está inserida. 
O tipo de aprendizagem é determinado pela maneira pela qual a modificação dos parâmetros ocorre (HAYKIN, 2001).

Segundo Tso e Mater (2009), para realização do aprendizado (treinamento), o número dos neurônios é igual ao número de vetores de características para entrada. Os neurônios da camada de saída têm que competir com os outros neurônios para haver interação entre os padrões de entrada. O resultado é a conexão dos pesos com o neurônio vencedor e os pesos de seus vizinhos são ajustados simultaneamente.

\section{Arquitetura da rede}

A maneira pela qual os neurônios de uma rede neural estão estruturados está intimamente ligada com o algoritmo de aprendizagem usado para treinar a rede. Em geral são identificadas duas classes de arquiteturas de rede fundamentalmente diferentes (HAYKIN, 2001) explicitadas nos itens a e b da figura 1.

Em uma rede neural, os neurônios estão organizados na forma de camadas. Na forma mais simples de uma rede de camadas (figura 1 a), tem-se uma camada de entrada de nós de entrada que se projeta sobre uma camada de saída de neurônios (nós computacionais), entretanto a recíproca não é verdadeira. Esta rede é chamada de rede de camada única, sendo que a designação "camada única" se refere à camada de saída de nós computacionais (neurônios).

Em redes com múltiplas camadas, há uma ou mais camadas ocultas, cujos nós computacionais são chamados correspondentemente de neurônios ocultos ou unidades ocultas. A habilidade dos neurônios ocultos é particularmente valiosa quando o tamanho da camada de entrada é grande. Os nós (neurônios) de entrada, como mostrado na figura 1-b, da camada de entrada da rede fornecem os respectivos elementos do padrão de ativação (vetor de entrada), que constituem os sinais de entrada aplicados aos neurônios (nós computacionais) na segunda camada. 


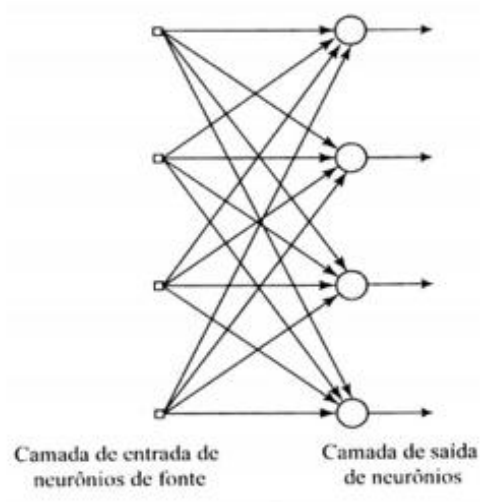

a)

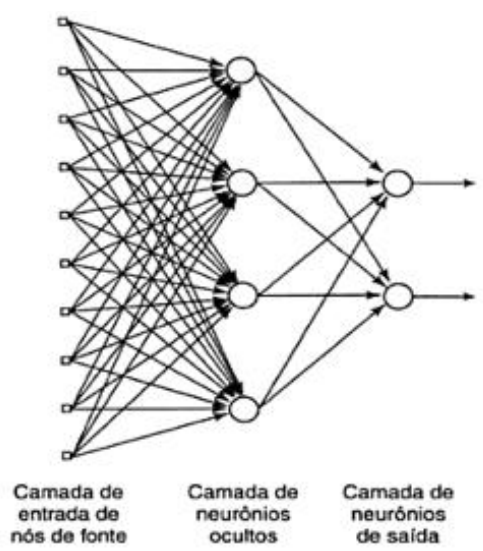

b)

Figura 1. (a) Rede de camada única. (b) Rede de múltiplas camadas.

Além do aprendizado e, portanto de treinamento dos dados de entrada para uma determinada saída da rede, ainda necessita-se das funções de ativação e transferência, para que os neurônios (nós) sejam ativados ou não e, transferidos para novas camadas e finalmente para a saída.

\section{Função de ativação e função de transferência}

A função de ativação antecede a função de transferência, e tem por atribuição, repassar o sinal para a saída do neurônio. É uma função de ordem interna, cuja atribuição é fazer acontecer um nível de ativação dentro do próprio neurônio, ou seja, é uma decisão tomada pelo neurônio sobre o que fazer com o valor resultante do somatório das entradas ponderadas (TAFNER et al, 1995).

A função de transferência pode ter muitas formas e métodos, podendo ser simples ou complexa. Esta função é que define e que envia para fora do neurônio o valor passado pela função de ativação (TAFNER et al, 1995).

\section{Materiais e métodos}

\section{Área de estudo}

A área de estudo dessa pesquisa, denominada Fazenda Escola Capão-da-Onça (FESCON) é administrada pela Universidade Estadual de Ponta Grossa (UEPG), no Município de Ponta Grossa, 
PR, latitude $25^{\circ} 05^{\prime} 35,7$ "S e longitude $50^{\circ} 03^{\prime} 19$ "W, com altitude em média de 1041 metros (FERREIRA et al. 2010 apud ORLOVSKI, 2013). A FESCON divide-se em duas áreas: experimental, onde fica a sede administrativa e outra de produção comercial com área de 2.181.166,29 $\mathrm{m}^{2}$, o que equivale a 218,11 hectares, cuja localização pode ser observada na figura 2.

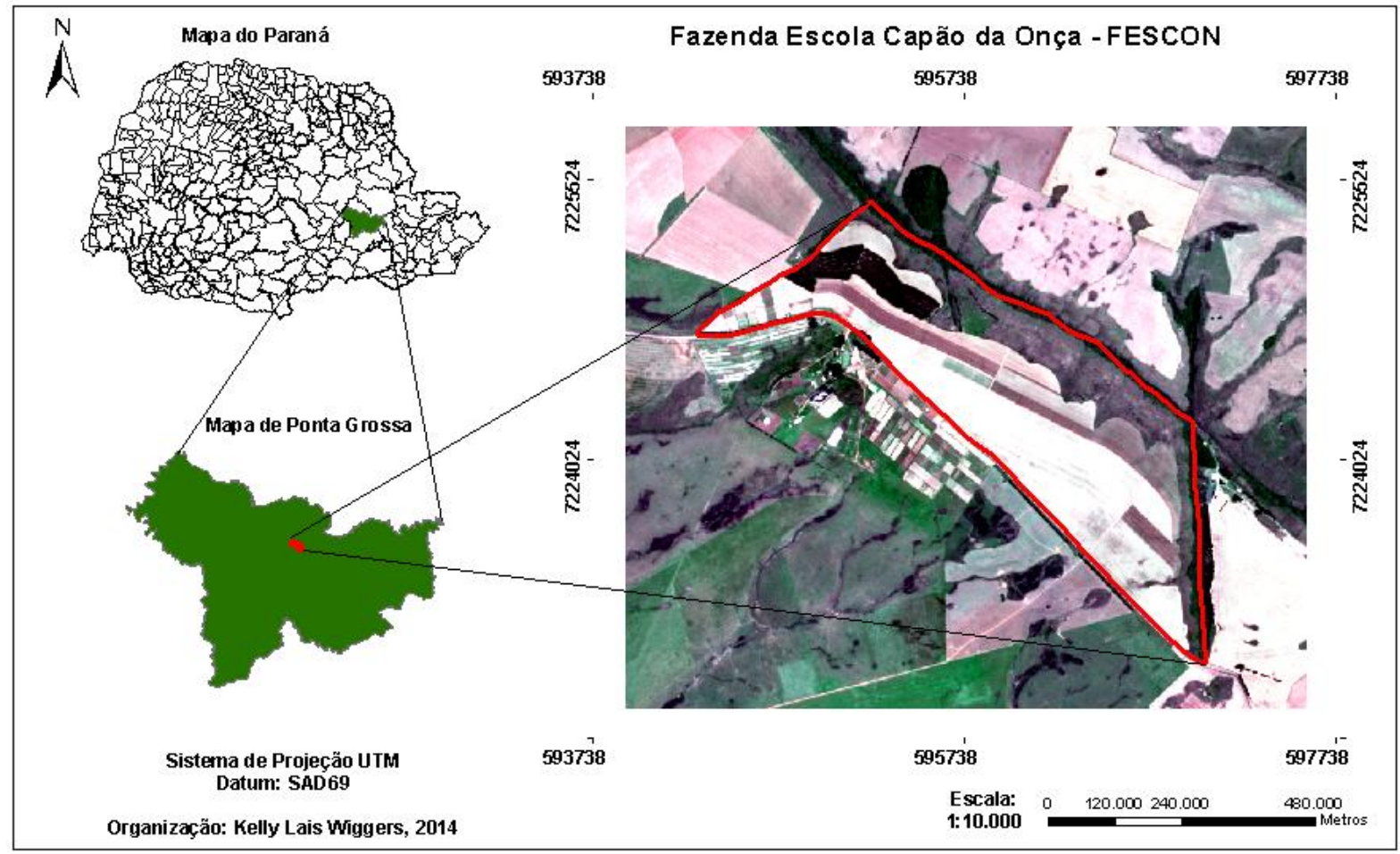

Figura 2. Localização da FESCON.

Na figura 3 apresenta-se o cartograma do relevo (a) e declividade (b), (c) surface e (d) wireframe da área de estudo, os quais são de importância em se tratando de estudos de textura de solos. A partir do vetor, apresentado no cartograma de relevo (hipsometria), foi interpolado e gerada a grade regular com espaçamento de 30 x 30 metros. Sobre esta grade foi realizado o modo de apresentação wireframe e surface, com a possibilidade da sobreposição (overlay) do vetor da área de estudo bem como da ortoimagem. Ambos estão posicionados com o ângulo de $318^{\circ}$ em leste-oeste e $42^{0}$ em norte-sul. 


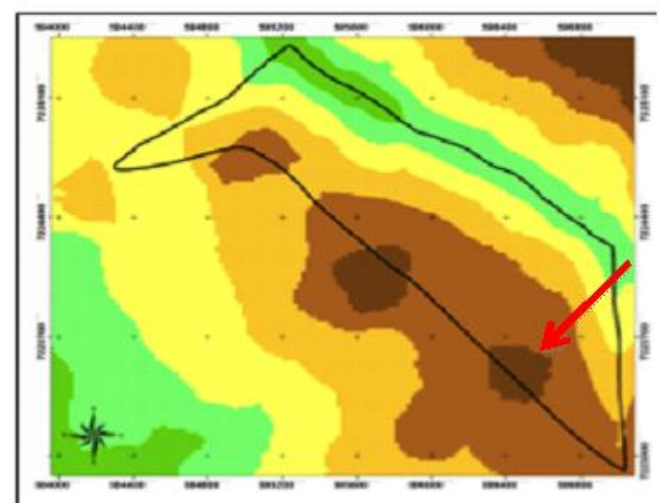

Altitude (metros)

920- 940

940- 960

960- 980

980 - 1.000

$1.000-1.020$

1.020- 1.040

(a)

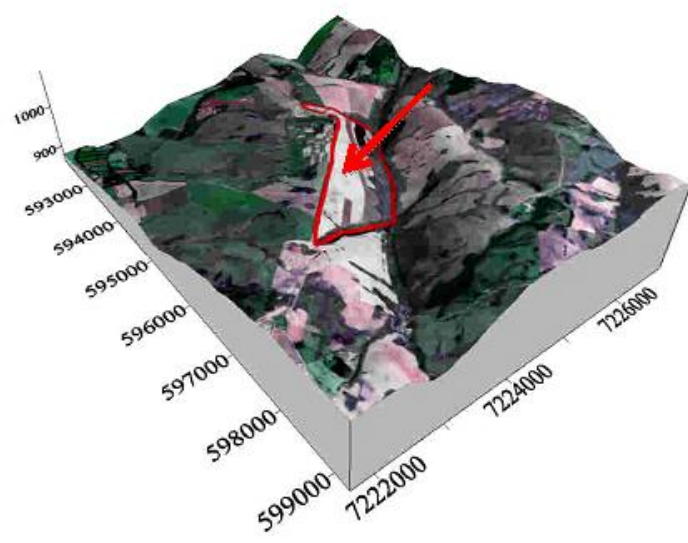

(c)

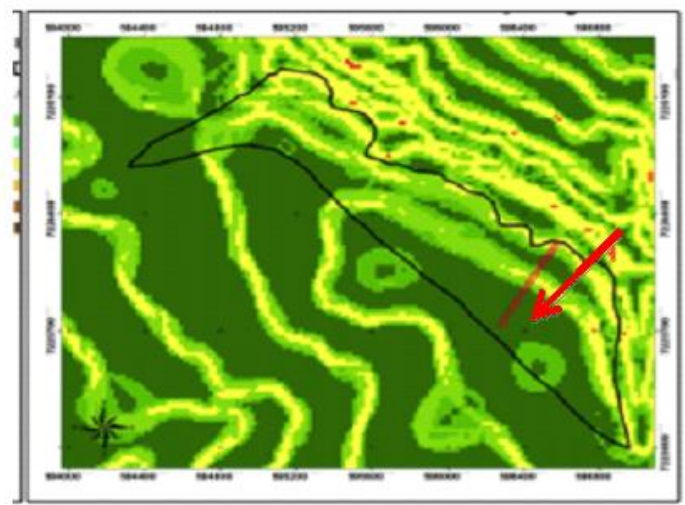

Declividade EMBRAPA (\%)

0 - 3 / Plano

3 - 8 / Suave Ondulado

- 8 - 20 / Ondulado

$\square 20$ - 45 / Forte Ondulado

$45-75$ / Montanhoso

$75-100$ / Escarpado

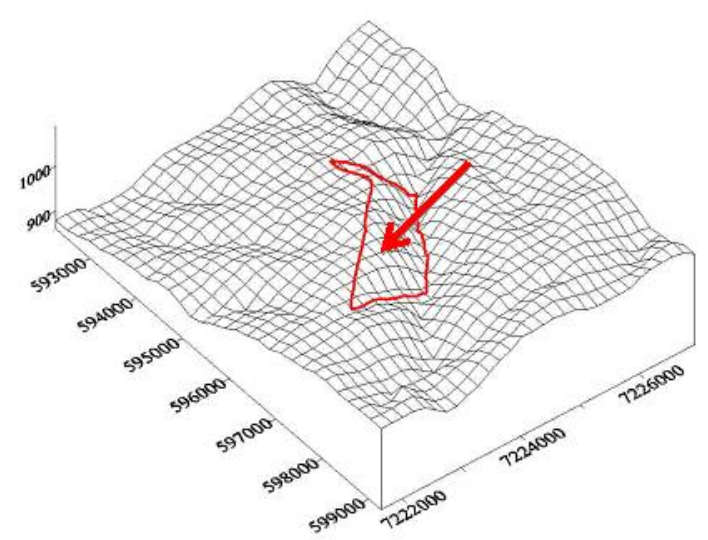

(d)

Figura 3. Cartograma de relevo (a), declividade (b), surface (c) e wireframe (d) da FESCON.

A figura 3 (a) representa as variações de altitude sendo a menor altitude em torno de 920 metros e a maior com 1040 metros, destaca-se aqui que o contorno preto corresponde a área de estudo e nota-se que a maior área encontra-se na altitude 980 a 1020 metros. A figura 3 (b) exibe as classes de declive que variam de 0-3\% plano a 75-100\% escarpado. Na área em questão as classes predominantes de declive são a plana, seguida da suave ondulada, ondulada e com menor representatividade a classe 
forte ondulada. Realizando-se uma análise visual, e na sobreposição do surface e wireframe , figuras 3 (c) e (d) respectivamente, nota-se que nos locais de maior altitude tem-se as menores declividades.

\section{Desenvolvimento do trabalho}

A figura 4 representa uma visão geral das etapas de desenvolvimento do trabalho. Os dados de entrada, sendo areia, silte e argila foram disponibilizados por Orlovski (2013), quando da sua dissertação e cedidos pelo Programa de Pós Graduação em Computação aplicada da UEPG para este estudo. Antes do treinamento destes vetores (areia, silte e argila), fez-se necessário separá-los entre dados de treinamento e de testes mediante scripts desenvolvido no software Matlab. Neste aplicativo, aplicou-se a RNA escolhida, e para finalização, a interpolação dos dados originais com o resultado da saída da RNA, para posterior análise dos resultados encontrados.

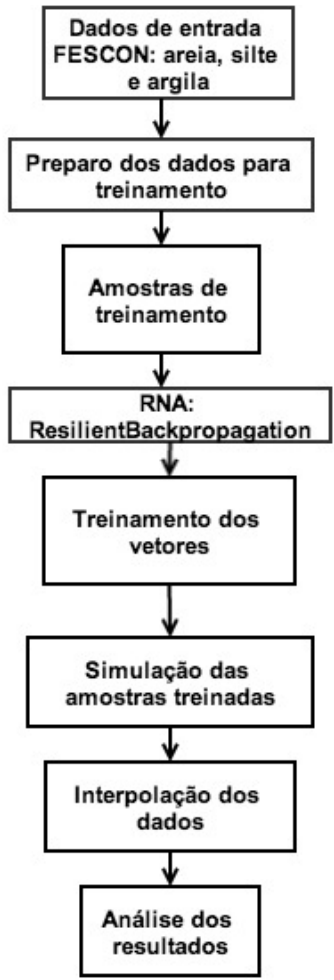

Figura 4. Diagrama de blocos correspondente às etapas de desenvolvimento.

A figura 5 é um exemplo de vetores de entrada (argila) para treinamento da RNA. Todos seguem o mesmo padrão para areia, silte e argila, compondo-se das coordenadas X e Y e os respectivos atributos 
de amostra para cada ponto utilizado. Totaliza-se 225 vetores com 4 posições cada. Destaca-se que a unidade de medida da areia, silte e argila é g/kg, e as coordenadas estão em metros.

$\begin{array}{llll}\text { Ponto } & \text { Coordenada X } & \text { Coordenada Y } & \text { argila } \\ 1 & 595991,138688 & 7223970,849100 & 455,07 \\ 2 & 596009,493045 & 7223961,614070 & 445,54 \\ 3 & 596027,736667 & 7223952,528990 & 336,95\end{array}$

Figura 5. Exemplo de vetores de entrada para treinamento da RNA presente na base de dados.

Após a definição das entradas (vetores de atributos de granulometria dos solos georreferenciados), foi escolhida a RNA e o algoritmo de treinamento. O algoritmo Backpropagation (BP) tem como objetivo encontrar na superfície de erro um mínimo global, ou seja, encontrar valores para os pesos sinápticos que minimizem o erro da rede. O BP utiliza pares de entrada e saída que ajustam os pesos da rede (HAYKIN, 1999), é uma rede neural artificia supervisionada a qual consiste na retropropagação dos erros em cada iteração. O Resilientbackpropagation (Rprop) é uma versão mais rápida do BP, ele trabalha com variação de sinal com o objetivo de reduzir rapidamente o erro de aprendizado (BRAUN e RIEDMILLER, 1993).

O software Matlab possui toolboxes específicas para o uso de RNA, estes apresentam funções: de inicialização da rede, transferência e ativação e ainda é responsável em criar a arquitetura de uma rede, com neurônios em camadas. O usuário precisa otimizar entradas (amostras de treinamento e de generalização - simulação) e saídas bem como definir o número de camadas, escolher as funções devido a complexidade dos vetores a serem treinados, ou seja do problema em questão.

Na figura 6 é possível verificar a estrutura da RNA implementada.

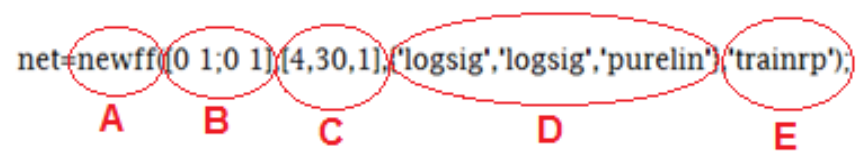

Figura 6. Exemplo de definição da RNA implementada. 
A função newff (ponto A) é responsável pela criação de uma rede neural do tipo Backpropagation, os valores do ponto B identificam o limite dos vetores de entrada que serão aplicados a rede neural, o ponto $\mathrm{C}$ identifica o número de neurônios que cada camada da rede neural irá possuir, ou seja, quatro neurônios na primeira camada - os quais correspondem aos vetores de entrada, trinta neurônios na segunda e uma única saída, no ponto D aplica a função de transferência em cada camada onde é definido o tipo de saída correspondente ao que se deseja na saída do neurônio e, no ponto E é onde se define o algoritmo de treinamento que a rede irá utilizar. $\mathrm{O}$ algoritmo que apresentou maior rapidez e melhores resultados foi o Resilient Backpropagation.

\section{Treinamento e configuração da rede neural}

As amostras utilizadas para o treinamento da RNA foram de 50\% do total de dados originais. $\mathrm{Na}$ figura 7, tem-se o script para coleta das amostras de treinamento, num total de 75 amostras. Ou seja, a planilha de dados é carregada, definindo-se o tamanho da matriz de treinamento. Todos os dados são separados em três arquivos com coordenadas x, y e um atributo (areia, silte e argila), e a cada duas amostras uma é coletada pra o treinamento.

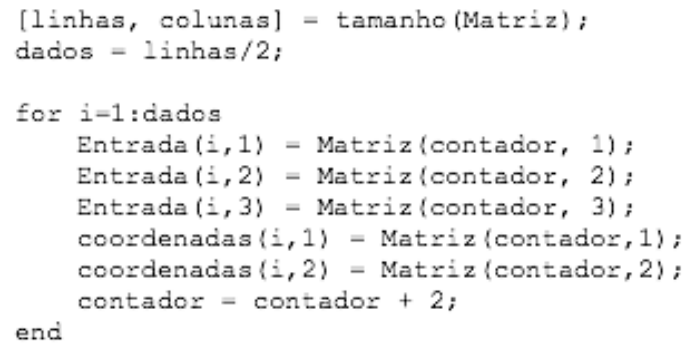

Figura 7. Escolha de amostras para treinamento.

Os dados de areia, silte e argila coletados no campo da FESCON - UEPG, foram organizados mediante o processamento do script exibido na figura 7. Após isso, são treinados na RNA da figura 6 e é gerada uma saída para cada uma das entradas (areia, silte, argila). Desta forma, arquivos de saída dos dados foram salvos e nomeados conforme o tipo de amostra, para futura plotagem no software Surfer 9. A figura 8 demonstra de forma ilustrativa como é formada a RNA implementada no software 
Matlab. A camada de entrada corresponde às posições de um vetor de entrada, composta de rótulo, coordenadas X e Y, areia, silte ou argila. Cada um destes nós (neurônios de entrada) é ligado aos neurônios das camadas intermediárias, e esta ligação contém os pesos iniciais, ajustados no decorrer do treinamento.

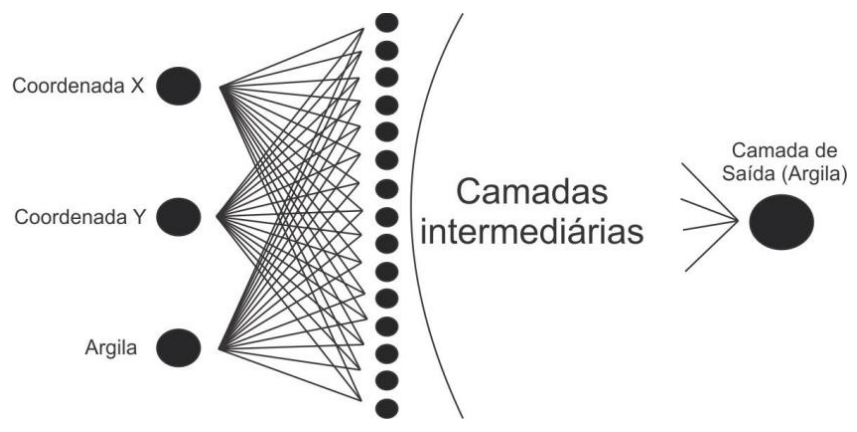

Figura 8. Arquitetura da RNA implementada.

\section{RESULTADOS E DISCUSSÕES}

Nesta seção os resultados das interpolações são apresentados, na forma de Blocos Diagrama (wireframe) e Mapas de Curvas de Contorno, ambos gerados no programa Surfer 9, referentes as interpolações de areia, argila e silte. Destaca-se que as interpolações foram mediante a técnica RBF implementada no programa citado e por meio do processamento no MatLab a RNA, sendo esta última especializada no programa Surfer 9 para as comparações a seguir. Ainda exibe-se os resultados das diferenças das grades interpoladas dos atributos mencionados na forma de gráfico.

A figura 9 apresenta o resultado na forma de bloco diagrama da interpolação do atributo areia mediante RBF (a) e com a RNA (b), respectivamente. Ambas as representações possuem giros de 310 graus em relação ao norte e de 45 graus em relação ao horizonte. As coordenadas estão no sistema UTM; no eixo x têm-se as abcissas, no eixo y são as coordenadas Norte e no eixo $\mathrm{Z}$ o atributo (areia). 

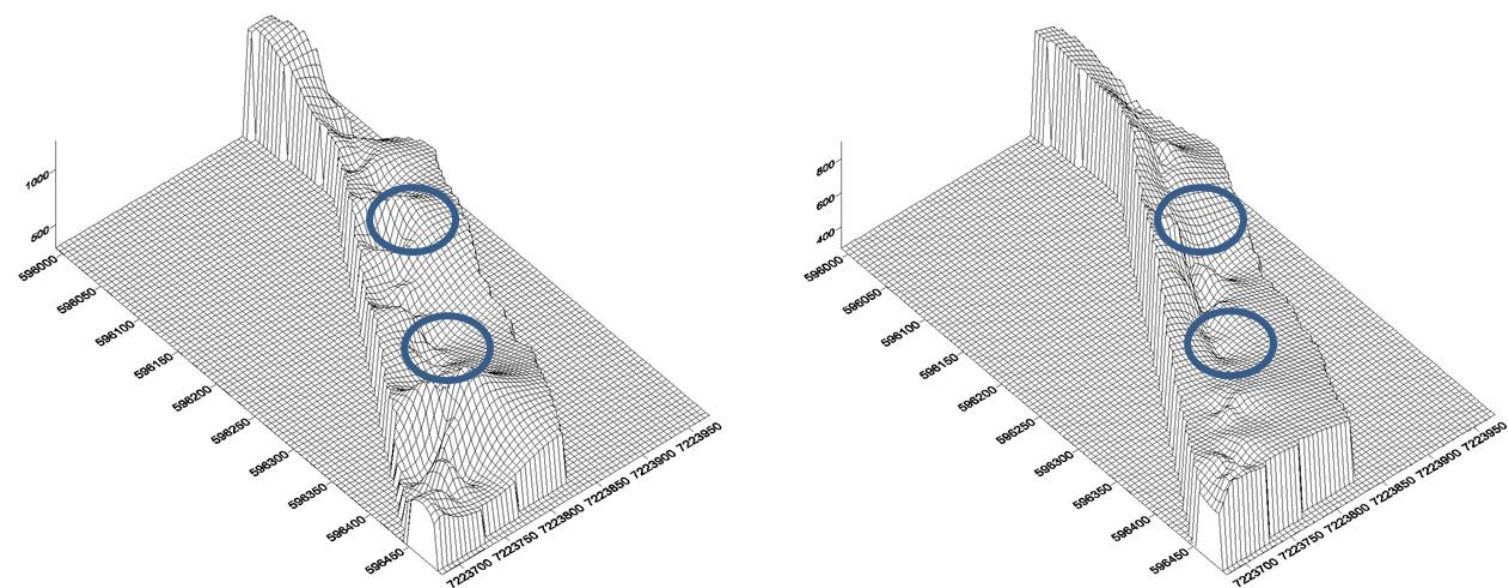

Figura 9. Bloco diagrama representando a areia, utilizando originais com interpolador RBF (a) e com RNA (b).

A figura 10 (a e b) apresenta a mesma interpolação do atributo areia na forma de curvas de contorno, aqui também destaca-se as diferenças ocorridas destacadas em forma de eclipses, entre as coordenadas $596.170 \mathrm{~m} \mathrm{E} \& 7.223 .825 \mathrm{~m} \mathrm{~N}$ e $596.305 \mathrm{~m}$ E \& 7.223.920m N e também entre as coordenadas $596.360 \mathrm{~m} \mathrm{E} \& 7.223 .745 \mathrm{~m} \mathrm{~N}$ e $596.455 \mathrm{~m}$ E e $7.223 .825 \mathrm{~m} \mathrm{~N}$, mostrando os locais onde a RNA suavizou mais as superfície que o interpolador spline RBF.
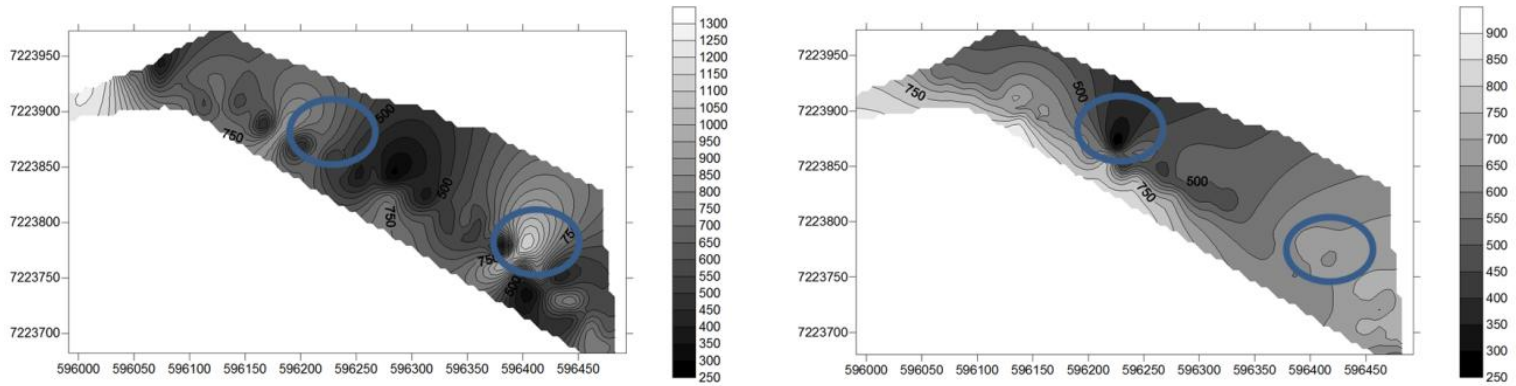

Figura 10. Mapa de contornos com dados de areia, utilizando originais com interpolador RBF (a) e com RNA (b).

Como análise destes resultados, pode-se considerar o gráfico 1 da figura 11. As maiores variações, entre as interpolações RBF versus RNA, foram entre as coordenadas ( x) 50 e 70 e atributos (y) 600 a 650 g.Kg-1 de areia. O eixo "Coordenadas" diz respeito aos pontos x e y do local onde foram coletadas as 150 amostras de solo, e o eixo "Areia" diz respeito ao valor do atributo que foi coletado. Nota-se em todas as representações que a RNA sempre suavizou mais quando da interpolação, fatos estes destacados no gráfico 1 da figura 11 com quatro (4) elipses. A tabela do Anexo 1 apresenta os E 
e $\mathrm{N}$ exatos, das 150 Coordenadas apresentadas no gráfico 1 da figura 11. Desta forma é possível verificar exatamente as coordenadas $\mathrm{E}$ e $\mathrm{N}$, previamente grifadas, de onde os valores foram suavizados pela RNA em comparação com a técnica RBF.

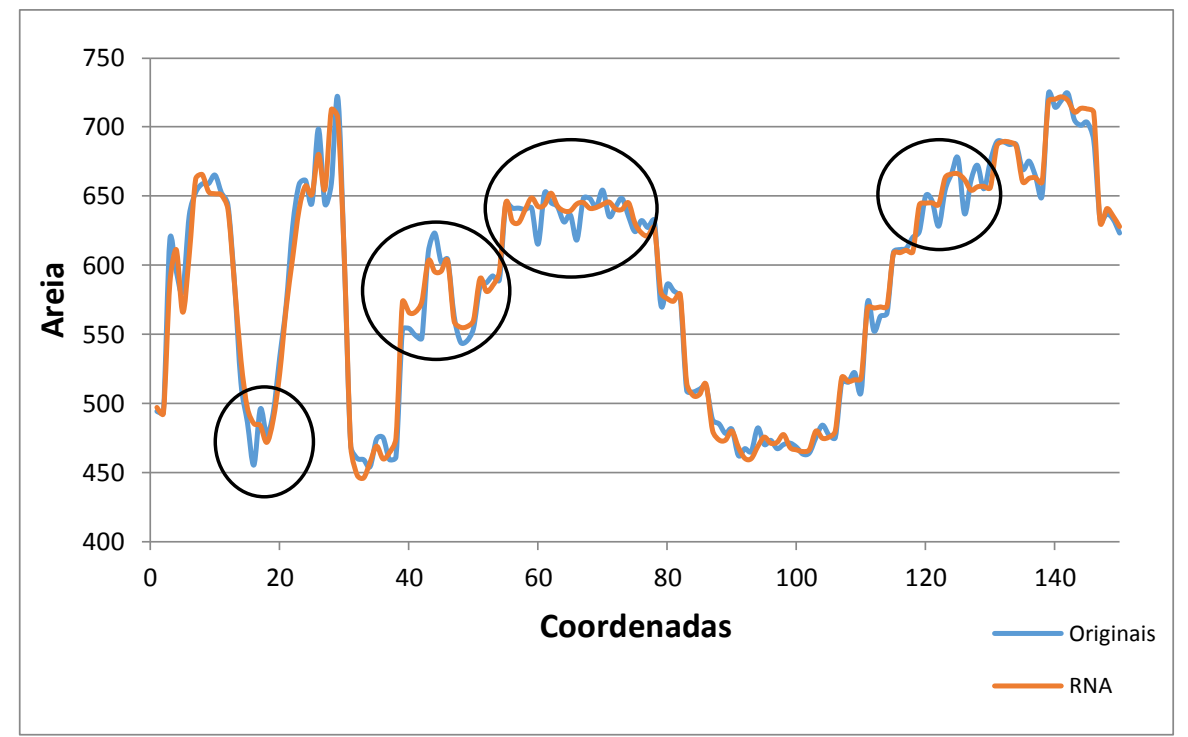

Figura 11. Comparação entre dados de areia RBF (originais) e treinados com RNA.

A figura 12 (a) mostra o resultado na forma de superfície da interpolação da argila mediante RBF e (b) com a RNA. Ambas as representações possuem giros de 310 graus em relação ao norte e de 45 graus em relação ao horizonte. As coordenadas estão no sistema UTM. No eixo x têm-se as abcissas. No eixo y são as coordenadas Norte e no eixo $\mathrm{Z}$ o atributo (argila).
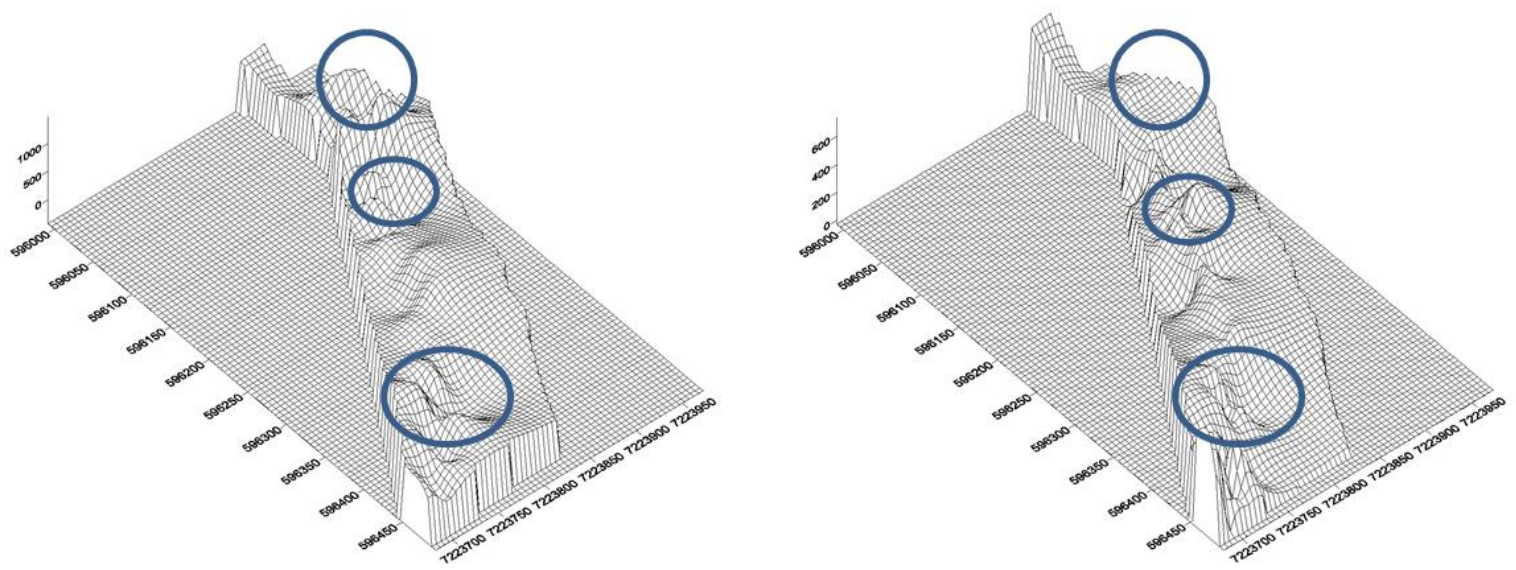

Figura 12. Bloco Diagrama representando a argila, utilizando originais com interpolador RBF (a) e com RNA (b). 
A figura 13 (a e b) apresenta a mesma interpolação do atributo argila na forma de curvas de contorno, aqui também destaca-se as diferenças ocorridas destacadas em forma de eclipses, entre as coordenadas 596160 E \& 7223860 N e 596249 E \& 7223942 N, e também entre as coordenadas 596360 E \& $7223750 \mathrm{~N}$ e 596456 E \& $7223810 \mathrm{~N}$ mostrando os locais onde a RNA suavizou mais as superfície que o interpolador spline - RBF.
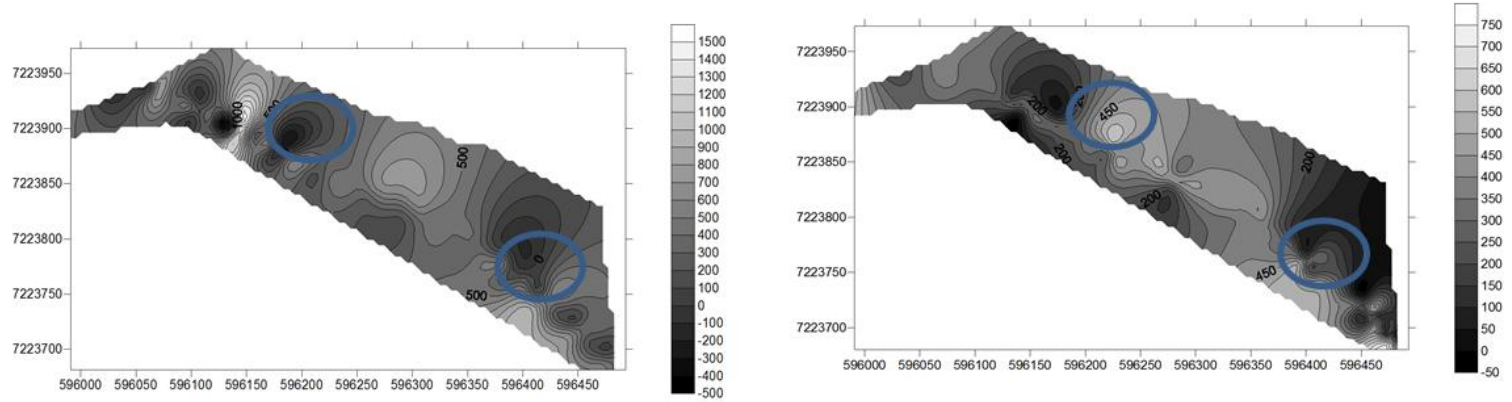

Figura 13. Mapa de contornos com dados de argila, utilizando originais com interpolador RBF (a) e com RNA

(b).

Como análise destes resultados, é possível ponderar no gráfico 2 da figura 14, que as maiores variações foram com coordenadas entre 40 e 70 e atributos 600 a 650 . Assim como ocorreu com a areia, nota-se em todas as representações que a RNA quando interpolou os dados de argila em relação ao RBF, suavizou mais a superfície, com exceção da área destaca em vermelho, no gráfico 2 da figura 12 e destacados com as quatro elipses e um retângulo em vermelho. Na tabela do Anexo 1 é possível verificar as coordenadas E e $\mathrm{N}$ exatas onde os valores foram suavizados pela RNA.

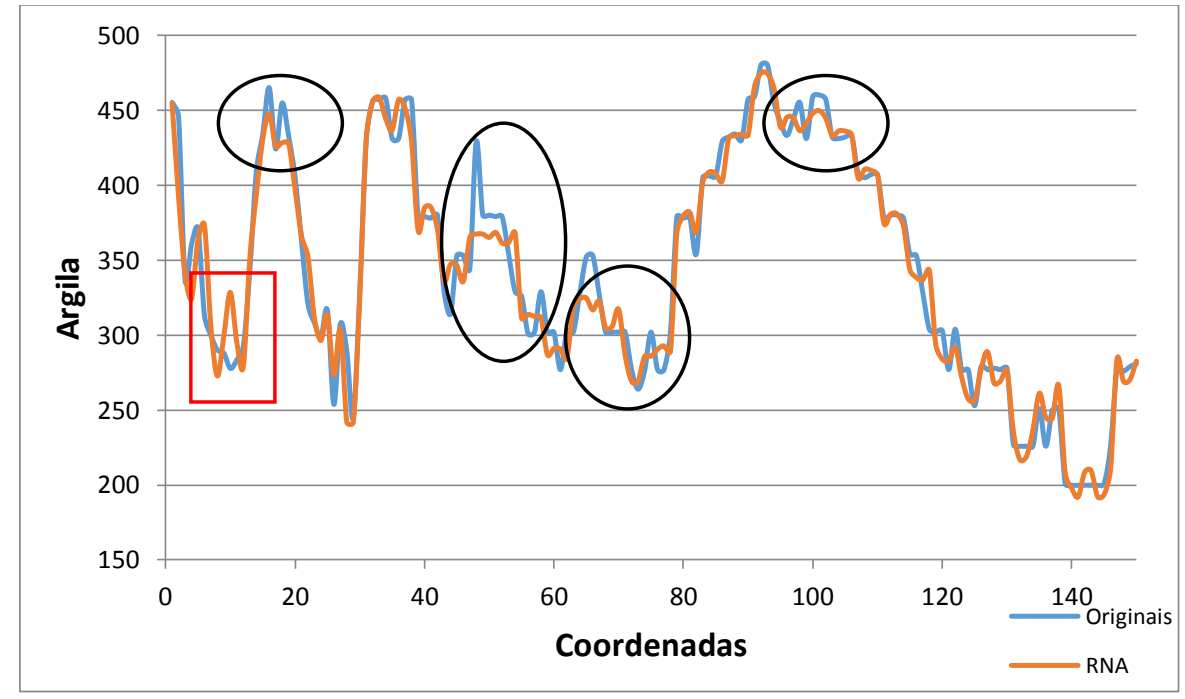

Figura 14. Comparação entre dados de argila RBF e treinados com RNA. 
A figura 15 (a) mostra o resultado na forma de superfície da interpolação da silte mediante RBF e (b) com a RNA. Ambas as representações possuem um giro de 310 graus em relação ao norte e um giro de 45 graus em relação ao horizonte. As coordenadas estão no sistema UTM e no eixo x têm-se as abcissas. No eixo y são as coordenadas Norte e no eixo Z o atributo (silte).
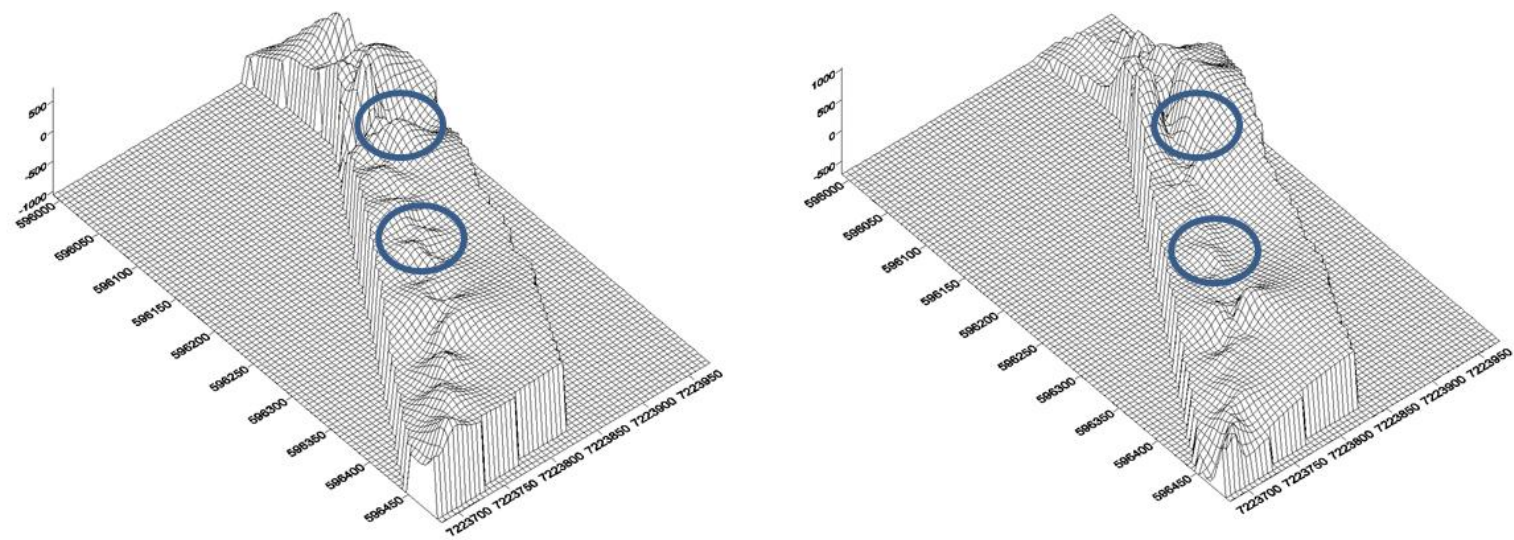

Figura 15. Bloco Diagrama representando o silte, utilizando originais com interpolador RBF (a) e com RNA (b).

A figura 16 ( $\mathrm{a}$ e b) apresenta a mesma interpolação do atributo silte na forma de curvas de contorno, aqui também destaca-se as diferenças ocorridas destacadas em forma de eclipses, entre as coordenadas 596110 E \& $7223850 \mathrm{~N}$ e 596210 E \& $7223930 \mathrm{~N}$, e também entre as coordenadas 596325 E \& $7223730 \mathrm{~N}$ e 596415 E \& $7223810 \mathrm{~N}$, mostrando os locais onde a RNA suavizou mais as superfície que o interpolador spline - RBF.
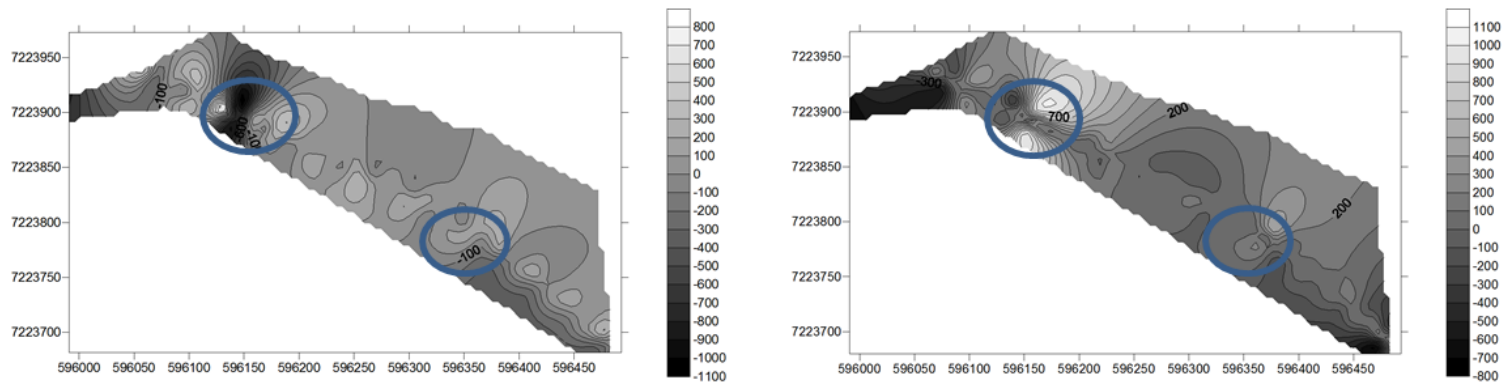

Figura 16. Mapa de contornos com dados de silte, utilizando originais com interpolador RBF (a) e com RNA (b).

Como análise destes resultados, é possível analisar no gráfico 3 da figura 17, que ocorreram muitas variações dos dados do interpolador comparado com a RNA. Com a areia e com a argila nota-se em 
todas as representações da RNA quando interpolou os dados em relação ao RBF, sempre suavizou mais a superfície, entretanto neste gráfico 3 da figura 17 a variação dos dados é mais abrupta que os demais já exibidos nas figuras, 13 e 15 e, na primeira elipse a RNA não suavizou os dados como nos demais. Na tabela do Anexo 1 é possível verificar as coordenadas E e N exatas onde os valores foram suavizados pela RNA.

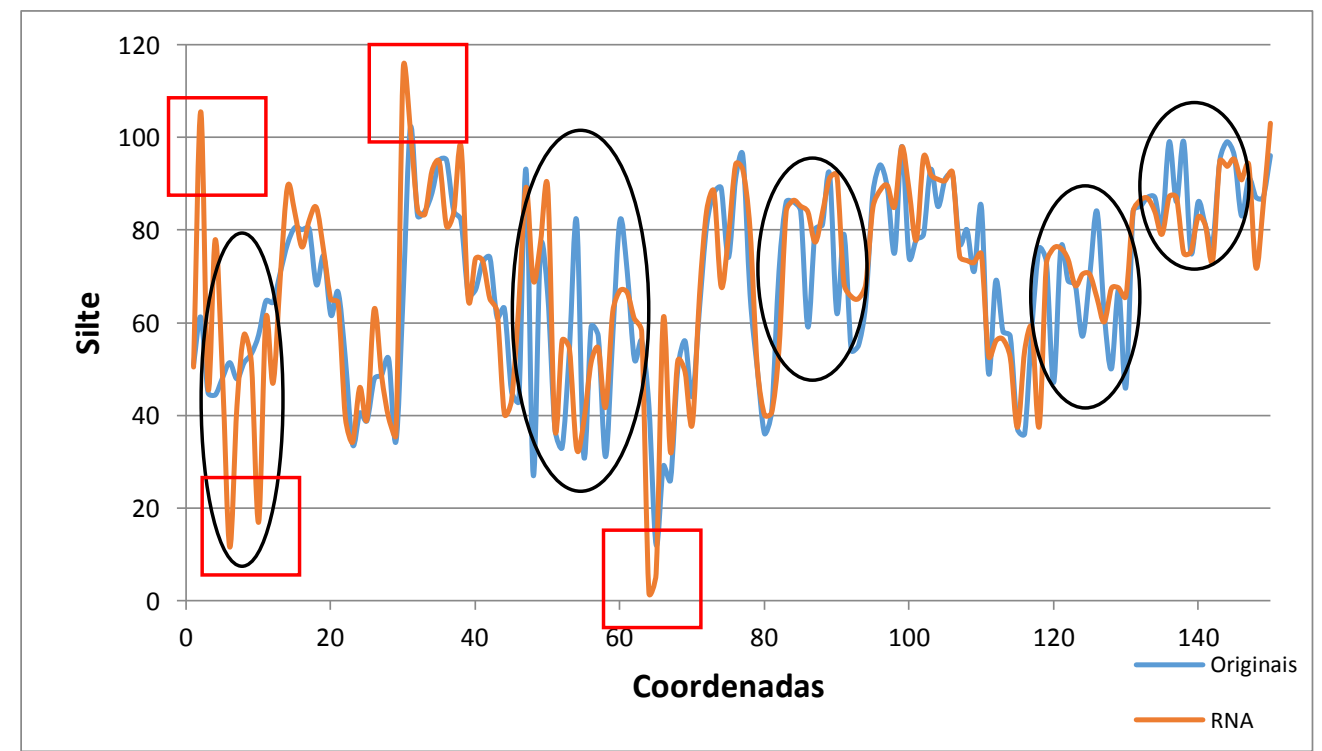

Figura 17. Comparação entre dados de silte originais e treinados com RNA.

\section{Conclusão}

Os dados georreferenciados, coletados da FESCON são bastante representativos e importantes para a espacialização granulométrica de solos, sendo possível realizar a interpolação utilizando o $\mathrm{RBF}$ e treinamento supervisionado por RNA. Desta forma, os resultados demonstraram-se significativos, permitindo análise das representações das superfícies a partir da RNA e RBF. E culminando na reflexão da importância do método de interpolação e como este pode alterar os dados quando da espacialização.

Os dados de areia foram os mais suavizados quando da utilização da RNA em contrapartida com a RBF. Nota-se principalmente a suavização dos dados por parte da RNA nas coordenadas N entre 596.200 e $596.400 \mathrm{~m}$ e E 7.223 .750 e 7.223.900m. Analisando-se a figura 10, MDT e declividade, 
esta é a porção sudeste (SE) nas altitudes de $960 \mathrm{~m}$ a $1020 \mathrm{~m}$ e com as declividades plana e suave ondulada.

Os dados de argila foram suavizados quando da utilização da RNA em contrapartida com a RBF, porém não tanto quanto os dados de areia. Foi possível verificar a suavização dos dados com a RNA nas coordenadas $\mathrm{N}$ entre 596.150 e $596300 \mathrm{~m}$ e E 7.223 .750 e $7.223 .900 \mathrm{~m}$ e analisando-se a figura 13, MDT e declividade, esta é a porção sudeste(SE) nas altitudes de $940 \mathrm{~m}$ a $1020 \mathrm{~m}$ e com as declividades plana e suave ondulada.

Os dados de silte também foram suavizados pela RNA em contrapartida com o RBF, entretanto não tanto quanto os dados de areia e argila. Verificou-se a suavização dos dados com a RNA nas coordenadas $\mathrm{N}$ entre 596.150 e $596.250 \mathrm{~m}$ e E 7.223 .800 e $7.223 .900 \mathrm{~m}$ e analisando-se a figura 16 , MDT e declividade, esta é a porção sudeste(SE) nas altitudes de 940m a 1020m e com as declividades plana e suave ondulada.

\section{Agradecimentos}

À Coordenação de Aperfeiçoamento de Pessoal de Nível Superior (CAPES) pelo apoio financeiro. Ao Programa de Pós-Graduação em Computação Aplicada do Departamento de Informática da UEPG pela disponibilidade do uso do software Matlab 9. À Mestre Regiane Orlovski pelo material disponibilizado para estudo. Ao laboratório de Geotecnologias do Departamento de Geociências da UEPG pela disponibilidade de uso das licenças dos softwares Surfer 9, ArcGis 9.

\section{REFERÊNCIAS}

ANTUNIASSI, U.; BAIO, F.; SHARP, T. Agricultura de Precisão e aplicação localizada de insumos. IN. VI Congresso Brasileiro de Algodão, 2007.

ASSAD, E.D.; SANO, E.E. Sistemas de informações geográficas (Aplicações na Agricultura). 2.ed. Brasília, DF: SPI/EMBRAPA-CPAC, 1998. p. 434.

BRADY, N. C; WEIL, R. R. The nature and properties of soils. 14th ed. New Jersey: Prentice Hall, 2008. 
BURROUGH, P.A. Principals of Geographical Information Systems for Land Resources Assessment. Oxford, Clarendon Press, 1986. p. 194.

CHEN, H.; LEOU, J. Saliency-directed color image interpolation using artificial neural network and particle swarm optimization. Journal of Visual Communication and Image Representation, v 23, p. 343-358, 2012.

GORGENS E., B. et al. Estimate of tree volume using artificial neural nets. Revista Árvore, Viçosa , v. 33, n. $6,2009$.

HAYKIN, S., Redes Neurais: Princípios e Prática. 2 ed. Editora Prentice Hall, Inc, 1999.

HAYKIN, S. Redes Neurais: Princípios e Prática. 2 ed. Porto Alegre: Bookman, 2001.

IBGE - Instituto Brasileiro De Geografia E Estatística. Manual Manual Téenico de Pedologia. Rio de Janeiro: IBGE, 2 ed 2007.

MAPA. Ministério da Agricultura, Pecuária e Abastecimento. Agricultura de precisão / Ministério da Agricultura, Pecuária e Abastecimento. Secretaria de Desenvolvimento Agropecuário e Cooperativismo. Brasília : Mapa/ACS, p. 36, 2011.

MAZZINI, P. L. F.; Schettini, C. A. F. Avaliação de metodologias de interpolação espacial aplicadas a dados hidrográficos costeiros quase- sinóticos. Braz. J. Aquat. Sci. Technol., 2009.

MOLIN, J. P.; Agricultura de precisão. Parte 1: O que é e estado da arte em sensoriamento. Engenharia Agrícola , v. 17 , f. 2 , p. 97-107, 1997.

NOURANI, V.; BABAKHANI, A.; Integration of Artificial Neural Networks with Radial Basis Function Interpolation in Earthfill Dam Seepage Modeling. Journal of Computing In Civil Engineering, v. 27, p 183-195, 2012.

ORLOVSKI, R. Avaliação de espaçamentos das coletas de solo para a modelagem de granulometria com aplicação na agricultura de precisão. (Dissertação) Universidade Estadual de Ponta Grossa, 2013.

PAIVA NETO, J. E. de. A "fração argila" dos solos do Estado de São Paulo e seu estudo roentgenográfico. Bragantia[online]. vol.2, n.10, p. 355-432, 1942.

REICHARDT, K.; TIMM, L. C. Solo, planta e atmosfera: conceito, processo e aplicaçôes. Barueri: Manóle, 2004.

REZENDE, S. O. (Org.). Sistemas Inteligentes: fundamentos e aplicações. São Paulo: Monole, 2005.

RIEDMILLER, M.; BRAUN, H. A direct adaptive method for faster back propagation learning: The RPROP algorithm. Proceedings of the IEEE International Conference on Neural Networks, 1993.

TAFNER, M. S.; et al. Redes Neurais Artificiais: Introdução e Princípios de Neurocomputação. Blumenau: Editora da FURB, 2005.

TSO, B.; MATHER, P. Classification methods for remotely sensed data. CRC Press: Taylor \& Francis Group, 2 ed. 356p, 2009.

\section{Anexos}

\begin{tabular}{|c|r|r|l|l|l|}
\hline Point & Coordinate $\mathbf{X}$ & Coordinate $\mathbf{Y}$ & Sand & Silt & Clay \\
\hline 1 & 595991,138688 & 7223970,849100 & 494,02 & 50,91 & 455,07 \\
\hline 2 & 596009,493045 & 7223961,614070 & 493,35 & 61,11 & 445,54 \\
\hline 3 & 596027,736667 & 7223952,528990 & 618,23 & 44,83 & 336,95 \\
\hline 4 & 596046,069386 & 7223944,244620 & 595,2 & 44,33 & 360,47 \\
\hline 5 & 596064,327566 & 7223934,886830 & 581,16 & 47,97 & 370,87 \\
\hline
\end{tabular}

\begin{tabular}{|c|c|c|c|c|c|}
\hline 6 & 596081,459233 & 7223926,663790 & 635,59 & 51,32 & 313,09 \\
\hline 7 & 596100,069796 & 7223916,914000 & 652,35 & 47,79 & 299,87 \\
\hline 8 & 596117,939104 & 7223908,391010 & 658,51 & 51,32 & 290,18 \\
\hline 9 & 596136,585910 & 7223899,695770 & 658,8 & 53,22 & 287,98 \\
\hline 10 & 596154,601640 & 7223890,968960 & 664,88 & 57,29 & 277,83 \\
\hline 11 & 596172,152052 & 7223882,875130 & 651,91 & 64,6 & 283,49 \\
\hline
\end{tabular}




\begin{tabular}{|c|c|c|c|c|c|}
\hline 12 & 596190,162351 & 7223874,059720 & 643,12 & 64,37 & 292,52 \\
\hline 13 & \begin{tabular}{|l|}
596208,328830 \\
\end{tabular} & 7223865,309010 & 587,1 & 70,77 & 342,13 \\
\hline 14 & 596226,426886 & 7223856,828550 & 514,67 & 76,94 & 408,39 \\
\hline 15 & 596244,615526 & 7223848,762720 & 486,15 & 80,44 & 433,41 \\
\hline 16 & \begin{tabular}{|l}
596262,529447 \\
\end{tabular} & 7223840,393640 & 455,11 & 80 & 464,89 \\
\hline 17 & 596280,671896 & 7223832,496350 & 495,69 & 80,21 & 424,1 \\
\hline 18 & 596298,466150 & 7223823,174120 & 477,2 & 68,12 & 454,68 \\
\hline 19 & 596316,677279 & 7223814,497390 & 492,92 & 74,3 & 432,79 \\
\hline 20 & 596334,058773 & 7223805,517650 & 532,81 & 61,58 & 405,61 \\
\hline 21 & 596351,917860 & 7223795,272310 & 570,93 & 66,53 & 362,54 \\
\hline 22 & \begin{tabular}{|l}
596368,954748 \\
\end{tabular} & 7223784,746060 & 627,36 & 52,21 & 320,43 \\
\hline 23 & 596384,716292 & 7223772,327680 & 658,13 & 33,66 & 308,21 \\
\hline 24 & 596400,700851 & 7223759,800330 & 661,07 & 40,42 & 298,51 \\
\hline 25 & \begin{tabular}{|l}
596415,757505 \\
\end{tabular} & 7223747,255230 & 644,76 & 38,82 & 316,43 \\
\hline 26 & 596431,199907 & 7223734,044760 & 698,31 & 47,78 & 253,91 \\
\hline 27 & 596446,118443 & 7223720,792440 & 644,06 & 48,56 & 307,39 \\
\hline 28 & \begin{tabular}{|l}
596461,006863 \\
\end{tabular} & 7223707,484340 & 658,83 & 52,04 & 289,13 \\
\hline 29 & 596475,928229 & 7223693,808980 & 721,08 & 34,25 & 244,67 \\
\hline 30 & 596490,025843 & 7223680,306170 & 604,63 & 66,02 & 329,35 \\
\hline 31 & \begin{tabular}{|l|}
595991,816505 \\
\end{tabular} & 7223971,832120 & 469 & 102 & 430 \\
\hline 32 & 595992,333350 & 7223972,709820 & 460 & 83 & 456 \\
\hline 33 & 595992,670352 & 7223972,632390 & 459 & 84 & 457 \\
\hline 34 & \begin{tabular}{|l}
595992,250081 \\
\end{tabular} & 7223972,222210 & 454 & 88 & 458 \\
\hline 35 & 59601 & 7223963,760970 & 474 & 95 & 431 \\
\hline 36 & 5960 & 7223 & 475 & 95 & 431 \\
\hline 37 & 596011,036388 & 7223964,140190 & 459 & 84 & 457 \\
\hline 38 & 596010,775203 & 7223963,170240 & 461 & 82 & 457 \\
\hline 39 & 596028,564726 & 7223954,280620 & 553 & 66 & 380 \\
\hline 40 & 596028,893172 & 7223955,095970 & 554 & 67 & 379 \\
\hline 41 & 59602 & 7223 & 549 & 73 & 378 \\
\hline 42 & 59602 & 72239 & 547 & 74 & 380 \\
\hline 43 & 596046,998865 & 7223945,084350 & 609 & 61 & 330 \\
\hline 44 & 596047,335977 & 7223946,016230 & 623 & 63 & 314 \\
\hline 45 & 596047,723955 & 7223945,739400 & 602 & 45 & 353 \\
\hline 46 & 596047,203484 & 7223944,943860 & 604 & 43 & 353 \\
\hline 47 & \begin{tabular}{|l}
596064,699862 \\
\end{tabular} & 7223936,557690 & 563 & 93 & 344 \\
\hline 48 & 596064,990278 & 7223937,382230 & 544 & 27 & 429 \\
\hline 49 & 596065,271742 & 7223937,016320 & 545 & 76 & 380 \\
\hline 50 & 596064,750051 & 7223936,326000 & 554 & 66 & 380 \\
\hline 51 & 596081,699733 & 7223928,513380 & 584 & 37 & 379 \\
\hline 52 & 596082,088096 & 7223929,403680 & 587 & 33 & 379 \\
\hline 53 & \begin{tabular}{|l}
596082,659241 \\
\end{tabular} & 7223928,923760 & 592 & 54 & 354 \\
\hline 54 & 596082,276153 & 7223927,947290 & 589 & 82 & 329 \\
\hline 55 & 596100,434858 & 7223918,710430 & 644 & 31 & 326 \\
\hline 56 & 596100,723438 & 7223920,068710 & 641 & 59 & 301 \\
\hline 57 & 596101,204131 & 7223919,989960 & 641 & 57 & 302 \\
\hline 58 & 596100,829235 & 7223919,102940 & 640 & 31 & 329 \\
\hline 59 & \begin{tabular}{|l}
596118,251613 \\
\end{tabular} & 7223910,480660 & 641 & 57 & 302 \\
\hline 60 & 596118,552136 & 109480 & 615 & 82 & 302 \\
\hline 61 & 596119,008699 & 7223910,747260 & 652 & 71 & 277 \\
\hline 62 & 596118,478897 & 7223909,939790 & 645 & 52 & 303 \\
\hline 63 & 596137,335147 & 7223901,390730 & 642 & 56 & 302 \\
\hline 64 & 596137,303277 & 7223902,074810 & 631 & 42 & 328 \\
\hline 65 & 7,720937 & 7223 & 636 & 12 & 352 \\
\hline 66 & 596137,633818 & 7223900,923190 & 618 & 29 & 353 \\
\hline 67 & 596155,293068 & 7223892,371170 & 648 & 26 & 327 \\
\hline 68 & 596155,621444 & 7223893,175750 & 648 & 50 & 302 \\
\hline 69 & 596155,946573 & 7223892,884900 & 642 & 56 & 302 \\
\hline 70 & 596155,684639 & 7223892,484990 & 654 & 44 & 302 \\
\hline 71 & 596172,418906 & 7223883,813350 & 635 & 63 & 302 \\
\hline 72 & 596172,812587 & 7223884,662700 & 642 & 81 & 277 \\
\hline 73 & 596173,270075 & 7223884,511190 & 648 & 88 & 264 \\
\hline 74 & 596172,971513 & 7223883,684250 & 635 & 89 & 276 \\
\hline 75 & 596190,588749 & 7223875,297670 & 624 & 74 & 302 \\
\hline 76 & 596190,966491 & 7223876,111140 & 632 & 91 & 277 \\
\hline 77 & 596191,568194 & 7223875,992760 & 627 & 96 & 277 \\
\hline 78 & 5961 & 722 & 632 & 66 & 302 \\
\hline 79 & 596208,637660 & 7223867,113830 & 571 & 50 & 379 \\
\hline 80 & \begin{tabular}{|l}
596209,022042 \\
\end{tabular} & 7223868,034300 & 586 & 36 & 378 \\
\hline 81 & 596209,466592 & 7223867,915180 & 581 & 41 & 378 \\
\hline 82 & 596209,216389 & 7223866,677520 & 576 & 71 & 354 \\
\hline 83 & 5962 & & 009 & 86 & 405 \\
\hline 84 & \begin{tabular}{|l}
596227,256352 \\
\end{tabular} & 7223859,728530 & 508 & 86 & 406 \\
\hline 85 & 596227,642630 & 7223859,291120 & 510 & 84 & 406 \\
\hline 86 & 596227,431972 & 7223858,457100 & 512 & 59 & 429 \\
\hline 87 & 596245,255267 & 7223850,341550 & 488 & 80 & 432 \\
\hline 88 & 596245,719276 & 7223850,875700 & 485 & 81 & 434 \\
\hline
\end{tabular}

\begin{tabular}{|c|c|c|c|c|c|}
\hline 89 & 596246,035085 & 7223850,693500 & 478 & 92 & 430 \\
\hline 90 & 596245,844100 & 7223850,027300 & 481 & 62 & 457 \\
\hline 91 & 596263,153342 & 7223841,830770 & 462 & 79 & 459 \\
\hline 92 & 596263,311922 & 7223842,549180 & 467 & 54 & 480 \\
\hline 93 & 596263,794139 & 7223842,329820 & 465 & 55 & 480 \\
\hline 94 & 596263,549336 & 7223841,579410 & 482 & 64 & 455 \\
\hline 95 & 596281,255965 & 7223833,292060 & 470 & 88 & 442 \\
\hline 96 & 596281,542286 & 7223833,693950 & 473 & 94 & 433 \\
\hline 97 & 596282,068593 & 7223833,411210 & 467 & 89 & 444 \\
\hline 98 & 596281,722865 & 7223832,887300 & 470 & 75 & 455 \\
\hline 99 & 596299,505463 & 7223824,452350 & 471 & 98 & 431 \\
\hline 100 & 596299,739394 & 7223825,130550 & 468 & 74 & 459 \\
\hline 101 & 596300,306991 & 7223825,101620 & 463 & 78 & 460 \\
\hline 102 & 596300,042131 & 7223824,605140 & 464 & 79 & 457 \\
\hline 103 & 596317,422297 & 7223815,870290 & 475 & 93 & 432 \\
\hline 104 & 596318,053238 & 7223816,599520 & 484 & 85 & 431 \\
\hline 105 & 596318,489518 & 7223816,420480 & 477 & 91 & 432 \\
\hline 106 & 596318,283691 & 7223815,755300 & 475 & 92 & 433 \\
\hline 107 & 596334,874571 & 7223806,877740 & 515 & 77 & 408 \\
\hline 108 & 596335,202745 & 7223807,810910 & 515 & 80 & 405 \\
\hline 109 & 596335,717990 & 7223807,548560 & 522 & 71 & 407 \\
\hline 110 & 596335,263284 & 7223807,142010 & 508 & 85 & 407 \\
\hline 111 & 596352,827240 & 7223796,912610 & 573 & 49 & 378 \\
\hline 112 & 596353,426629 & 7223797,537160 & 552 & 69 & 380 \\
\hline 113 & 596353,916381 & 7223797,393420 & 563 & 58 & 380 \\
\hline 114 & 596353,361784 & 7223796,567050 & 565 & 57 & 378 \\
\hline 115 & 596370,024387 & 7223785,796420 & 609 & 37 & 354 \\
\hline 116 & 596370,403162 & 7223786,556660 & 611 & 36 & 353 \\
\hline 117 & 596370,930515 & 7223786,303440 & 612 & 59 & 328 \\
\hline 118 & 596370,358189 & 7223785,505200 & 620 & 76 & 304 \\
\hline 119 & 596385,773454 & 7223773,910930 & 624 & 73 & 302 \\
\hline 120 & 596386,167846 & 7223774,700900 & 650 & 47 & 303 \\
\hline 121 & 596386,565511 & 7223774,369540 & 646 & 76 & 277 \\
\hline 122 & 596386,172374 & 7223773,717380 & 628 & 69 & 304 \\
\hline 123 & 596401,711078 & 7223761,242720 & 654 & 68 & 277 \\
\hline 124 & 596402,162429 & 7223762,006440 & 666 & 57 & 277 \\
\hline 125 & 596402,576334 & 7223761,713730 & 677 & 70 & 253 \\
\hline 126 & 596402,111247 & 7223760,433910 & 637 & 84 & 279 \\
\hline 127 & 596416,917939 & 7223748,271110 & 661 & 62 & 277 \\
\hline 128 & 596417,601065 & 7223749,170080 & 672 & 50 & 278 \\
\hline 129 & 596417,943705 & 7223748,821580 & 655 & 67 & 277 \\
\hline 130 & 596417,668328 & 7223748,581120 & 675 & 46 & 278 \\
\hline 131 & 596432,551596 & 7223735,565940 & 689 & 84 & 227 \\
\hline 132 & 596433,175269 & 7223736,257380 & 689 & 85 & 226 \\
\hline 133 & 596433,518088 & 7223735,775980 & 687 & 87 & 226 \\
\hline 134 & 596433,079039 & 7223734,969720 & 687 & 87 & 226 \\
\hline 135 & 596447,573215 & 7223722,076020 & 669 & 81 & 251 \\
\hline 136 & 596448,135865 & 7223722,654680 & 675 & 99 & 226 \\
\hline 137 & 596448,631740 & 7223722,268490 & 664 & 86 & 250 \\
\hline 138 & 596447,921568 & 7223721,426930 & 650 & 99 & 251 \\
\hline 139 & 596462,243424 & 7223709,084470 & 724 & 75 & 201 \\
\hline 140 & 596462,758842 & 7223709,520110 & 714 & 86 & 200 \\
\hline 141 & 596463,391812 & 7223709,308900 & 719 & 81 & 200 \\
\hline 142 & 596462,675948 & 7223708,415090 & 724 & 77 & 200 \\
\hline 143 & 596477,095303 & 7223695,010920 & 705 & 95 & 200 \\
\hline 144 & 596478,015509 & 7223695,647030 & 701 & 99 & 200 \\
\hline 145 & 596478,508302 & 7223695,181800 & 703 & 96 & 201 \\
\hline 146 & 596477,562243 & 7223694,613240 & 690 & 83 & 226 \\
\hline 147 & 596491,587861 & 7223681,742490 & 632 & 91 & 277 \\
\hline 148 & 596492,230087 & 7223682,324280 & 637 & 87 & 276 \\
\hline 149 & 596492,779815 & 7223681,948470 & 633 & 87 & 279 \\
\hline 150 & 596492,106263 & 7223681,531480 & 623 & 96 & 281 \\
\hline
\end{tabular}

Anexo 1. Valores das coordenadas X, Y e atributos Areia, Argila e Silte. 